\title{
Multiobjective Optimization Design of Spinal Pedicle Screws Using Neural Networks and Genetic Algorithm: Mathematical Models and Mechanical Validation
}

\author{
Yongyut Amaritsakul, ${ }^{1}$ Ching-Kong Chao, ${ }^{1}$ and Jinn Lin $^{2}$ \\ ${ }^{1}$ Department of Mechanical Engineering, National Taiwan University of Science and Technology 43, \\ Section 4, Keelung Road, Taipei 106, Taiwan \\ ${ }^{2}$ Department of Orthopaedic Surgery, National Taiwan University Hospital 7, Chung-Shun South Road, Taipei 100, Taiwan
}

Correspondence should be addressed to Jinn Lin; jinn@ntu.edu.tw

Received 6 June 2013; Accepted 8 July 2013

Academic Editor: Zhonghua Sun

Copyright (C) 2013 Yongyut Amaritsakul et al. This is an open access article distributed under the Creative Commons Attribution License, which permits unrestricted use, distribution, and reproduction in any medium, provided the original work is properly cited.

\begin{abstract}
Short-segment instrumentation for spine fractures is threatened by relatively high failure rates. Failure of the spinal pedicle screws including breakage and loosening may jeopardize the fixation integrity and lead to treatment failure. Two important design objectives, bending strength and pullout strength, may conflict with each other and warrant a multiobjective optimization study. In the present study using the three-dimensional finite element (FE) analytical results based on an $\mathrm{L}_{25}$ orthogonal array, bending and pullout objective functions were developed by an artificial neural network (ANN) algorithm, and the trade-off solutions known as Pareto optima were explored by a genetic algorithm (GA). The results showed that the knee solutions of the Pareto fronts with both high bending and pullout strength ranged from $92 \%$ to $94 \%$ of their maxima, respectively. In mechanical validation, the results of mathematical analyses were closely related to those of experimental tests with a correlation coefficient of -0.91 for bending and 0.93 for pullout $(P<0.01$ for both). The optimal design had significantly higher fatigue life $(P<0.01)$ and comparable pullout strength as compared with commercial screws. Multiobjective optimization study of spinal pedicle screws using the hybrid of ANN and GA could achieve an ideal with high bending and pullout performances simultaneously.
\end{abstract}

\section{Introduction}

The treatment goals of spinal fractures include deformity correction, neurological decompression, and fixation of the instability [1]. Transpedicle screw fixators can achieve reduction, decompression, and fixation at the same time, and provide high fixation stability for early mobilization [2-4]. One important principle of spinal fixation is to minimize the instrumentation levels to reduce the surgical trauma, preserve the motion segments, and avoid junctional arthritis and late back pain caused by long-segment instrumentation which may increase load at the adjacent segments [5]. However, relatively high failure rates with this short-segment instrumentation which fixes only one level above and below the fractured vertebra have been reported [1]. Failure of the pedicle screws including breakage and loosening may jeopardize the fixation integrity and lead to treatment failure [68]. Especially, broken pedicle screws trapped in the vertebral bodies are difficult to retrieve and may interfere with subsequent revision surgeries [9]. Thus, the design rationale of pedicle screws is to increase bending strength to resist breakage and pullout strength to resist loosening simultaneously [10-12]. However, these two design objectives are closely related to the screws' structures and may conflict with each other $[10,13-15]$. Improving one objective may cause deterioration of the other. Therefore, optimization studies to improve both design objectives simultaneously are critical but still rare in the literature [16]. 


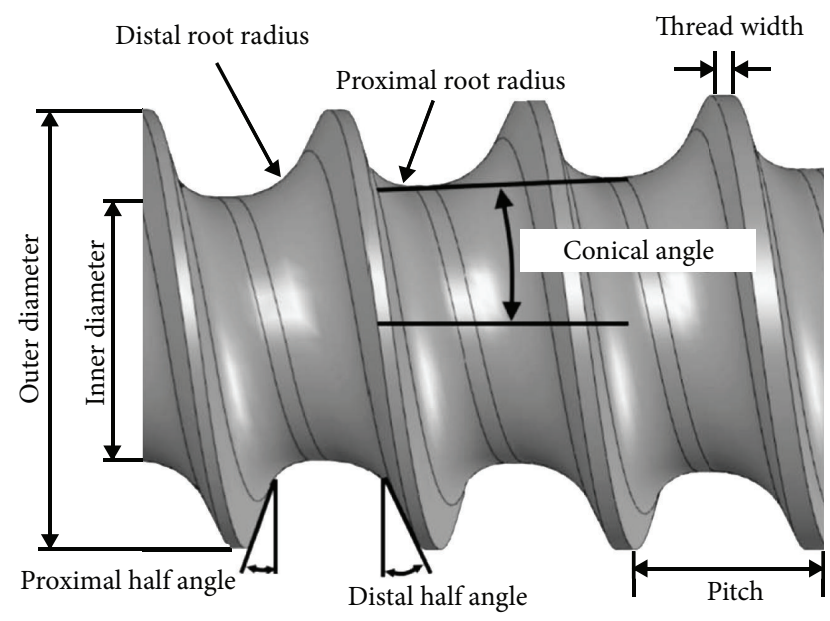

FIGURE 1: Illustration of structural variables for the spinal pedicle screw.

In the present study, computer aided engineering (CAE) with high calculation technology was applied. The pedicle screws were analyzed with finite element (FE) models, and then artificial neural network (ANN) algorithms were adopted to model the analytical process. The optimal screw design was achieved via an evolutionary multiobjective approach with a genetic algorithm (GA) [15]. Last, mechanical tests were conducted to validate the optimal design by comparison with commercially available devices.

\section{Materials and Methods}

2.1. Screw Structures and Orthogonal Array of Taguchi Robust Design Methods [15]. In this study the outer diameter of the pedicle screws was fixed at $7 \mathrm{~mm}$. Among the eight independent structural variables of pedicle screws, six of them were analyzed including beginning position of conical angle (BP), inner diameter (ID) at the screw tip, proximal root radius (PRR), pitch $(\mathrm{P})$, proximal half angle (PHA), and thread width (TW) (Figure 1). The design space of these structural variables was determined according to commonly used pedicle screws and previous studies $[1,15]: 0-36 \mathrm{~mm}$ for BP, 3.8-5.5 mm for ID, 0.4-1.0 mm for PRR, 2.6-4.0 $\mathrm{mm}$ for $\mathrm{P}, 5-20^{\circ}$ for PHA, and $0.1-0.3 \mathrm{~mm}$ for TW (Table 1 ). The distal root radius and distal half angle were fixed at $1 \mathrm{~mm}$ and $25^{\circ}$, respectively, because of minimal effects on the mechanical performance of the screws $[17,18]$. An $\mathrm{L}_{25}$ orthogonal array for six factors with five levels was selected for optimization study. This orthogonal array ensures a balanced comparison of levels of each structural variable and represents the entire experimental space. The structural variables were equally divided to 5 levels and put in the $\mathrm{L}_{25}$ orthogonal array. All the screw designs in the orthogonal array fulfilled the geometric constraints [15].

2.2. FE Models. Three-dimensional solid models of the spinal pedicle screws inserted at the center of a cylinder were first created by the CAD software SolidWorks 2005 (SolidWorks, Concord, MA, USA) and then imported into the CAE software ANSYS 10 Workbench (ANSYS Inc., Canonsburg, PA, USA) with the use of the Parasolid format (Figure 2). The screw was $45 \mathrm{~mm}$, and the cylinder was $60 \mathrm{~mm}$ in length. The pedicle screw was free-meshed with high order 10node tetrahedral elements, and the cylinder was map-meshed with 20-node hexahedral elements with the element size of $1.2 \mathrm{~mm}$. Surface-to-surface contact elements were used for the interface between the pedicle screw and cylinder with a frictionless condition. No axial rotation of the constructs was allowed. The elastic modulus of titanium pedicle screws was $114 \mathrm{GPa}$. The Poisson's ratio was 0.3 for both pedicle screw and cylinder. The thread valleys with stress concentration were remeshed, and the numerical convergence was confirmed by increasing mesh density.

For bending strength, a cantilever bending setup was used to simulate the worst-case scenario of total corpectomy conditions. The cylinders with an outer diameter of $20 \mathrm{~mm}$ were made from homogeneous polyoxymethylene with an elastic modulus of $2.6 \mathrm{GPa}$. The screw head was constrained, and a compressive force of $225 \mathrm{~N}$ was applied to the cylinder with a lever arm of $40 \mathrm{~mm}$ (Figure 2(a)). In the postprocessing, the maximum tensile stress of the pedicle screw was recorded to represent the bending strength. Lower maximum tensile stress represented longer fatigue life and higher bending strength, and vice versa. For pullout strength, to simulate the worst case scenario of osteoporosis, the cylinder with an outer diameter of $30 \mathrm{~mm}$ was assumed to be osteoporotic bone with an elastic modulus of $137.5 \mathrm{MPa}$. The effects of bone compaction caused by conical screws were simulated by adjusting the elastic modulus of the bone surrounding the conical core according to the density change of the surrounding bone [11]. Density change was calculated on the basis of the volume reduction caused by the compaction. The elastic modulus of bone was assumed to be a power-law function of the density with an exponent of 2 . In the loading condition, an axial displacement of $0.01 \mathrm{~mm}$ was applied to the end surface of the pedicle screw. The boundary conditions were constraints at the outer surface of the cylinder (Figure 2(b)). In the postprocessing, total reaction force on screws, defined as the summation of the resultant axial force at the surface of the screw, was recorded. Higher total reaction force represented stronger pullout strength.

\subsection{Artificial Neural Network Modeling. ANN as a regression} device containing layers of computing nodes with remarkable information processing capability can detect nonlinearities by machine learning and adaptability based on the leastsquares algorithm [19]. In the current study, because of the complexity of FE analyses, ANN was used to replace the FE models of bending strength and pullout strength for construction of the objective functions for multiobjective optimization studies. The supervised feed-forward errorbackpropagation learning models with sigmoid activation function were developed. Six structural variables were used as inputs, and single output was either maximum tensile stress or total reaction force (Figure 3). A three-layered ANN based on the 25 screw designs in the orthogonal array with three neurons in one hidden layer was used as the learning set. Another testing set with 10 randomly selected screw designs 
TABLE 1: Design variables of the pedicle screws, FE analytical results and ANN models.

\begin{tabular}{|c|c|c|c|c|c|c|c|c|c|c|}
\hline \multicolumn{2}{|c|}{ No. BP $(\mathrm{mm})$} & \multirow{2}{*}{$\frac{\mathrm{ID}(\mathrm{mm})}{3.80}$} & \multirow{2}{*}{$\begin{array}{c}\text { PRR }(\mathrm{mm}) \\
0.40\end{array}$} & \multirow{2}{*}{$\begin{array}{c}\mathrm{P}(\mathrm{mm}) \\
2.60\end{array}$} & \multirow{2}{*}{$\frac{\mathrm{PHA}\left({ }^{\circ}\right)}{5.00}$} & \multirow{2}{*}{$\frac{\text { TW }(\mathrm{mm})}{0.10}$} & \multirow{2}{*}{$\frac{\text { MTS-FE (MPa) }}{464.49}$} & \multirow{2}{*}{$\begin{array}{c}\text { MTS-ANN }(\mathrm{MPa}) \\
464.71\end{array}$} & \multirow{2}{*}{$\begin{array}{c}\text { TRF-FE }(\mathrm{N}) \\
39.93\end{array}$} & \multirow{2}{*}{$\begin{array}{c}\text { TRF-ANN }(\mathrm{N}) \\
39.99\end{array}$} \\
\hline 1 & 0 & & & & & & & & & \\
\hline 2 & 0 & 4.23 & 0.55 & 2.95 & 8.75 & 0.15 & 416.30 & 415.05 & 38.40 & 38.59 \\
\hline 3 & 0 & 4.65 & 0.70 & 3.30 & 12.50 & 0.20 & 399.83 & 392.63 & 35.56 & 35.75 \\
\hline 4 & 0 & 5.08 & 0.85 & 3.65 & 16.25 & 0.25 & 377.19 & 382.49 & 31.37 & 31.26 \\
\hline 5 & 0 & 5.50 & 1.00 & 4.00 & 20.00 & 0.30 & 380.56 & 377.39 & 26.36 & 26.48 \\
\hline 6 & 9 & 3.80 & 0.55 & 3.30 & 16.25 & 0.30 & 452.25 & 457.14 & 38.37 & 38.38 \\
\hline 7 & 9 & 4.23 & 0.70 & 3.65 & 20.00 & 0.10 & 415.59 & 419.10 & 36.48 & 36.57 \\
\hline 8 & 9 & 4.65 & 0.85 & 4.00 & 5.00 & 0.15 & 404.94 & 405.94 & 33.66 & 33.72 \\
\hline 9 & 9 & 5.08 & 1.00 & 2.60 & 8.75 & 0.20 & 432.04 & 427.96 & 33.96 & 33.82 \\
\hline 10 & 9 & 5.50 & 0.40 & 2.95 & 12.50 & 0.25 & 393.19 & 404.48 & 35.67 & 35.54 \\
\hline 11 & 18 & 3.80 & 0.70 & 4.00 & 8.75 & 0.25 & 468.89 & 468.30 & 36.74 & 36.80 \\
\hline 12 & 18 & 4.23 & 0.85 & 2.60 & 12.50 & 0.30 & 576.54 & 574.13 & 37.94 & 37.90 \\
\hline 13 & 18 & 4.65 & 1.00 & 2.95 & 16.25 & 0.10 & 444.50 & 437.91 & 35.72 & 35.71 \\
\hline 14 & 18 & 5.08 & 0.40 & 3.30 & 20.00 & 0.15 & 429.80 & 416.79 & 36.65 & 36.33 \\
\hline 15 & 18 & 5.50 & 0.55 & 3.65 & 5.00 & 0.20 & 391.64 & 397.72 & 33.37 & 33.49 \\
\hline 16 & 27 & 3.80 & 0.85 & 2.95 & 20.00 & 0.20 & 608.56 & 617.34 & 37.47 & 37.15 \\
\hline 17 & 27 & 4.23 & 1.00 & 3.30 & 5.00 & 0.25 & 532.07 & 529.34 & 36.37 & 36.23 \\
\hline 18 & 27 & 4.65 & 0.40 & 3.65 & 8.75 & 0.30 & 491.02 & 481.84 & 36.73 & 36.58 \\
\hline 19 & 27 & 5.08 & 0.55 & 4.00 & 12.50 & 0.10 & 460.59 & 463.83 & 34.67 & 34.41 \\
\hline 20 & 27 & 5.50 & 0.70 & 2.60 & 16.25 & 0.15 & 463.35 & 469.46 & 35.14 & 35.44 \\
\hline 21 & 36 & 3.80 & 1.00 & 3.65 & 12.50 & 0.15 & 919.85 & 918.26 & 35.19 & 35.31 \\
\hline 22 & 36 & 4.23 & 0.40 & 4.00 & 16.25 & 0.20 & 787.66 & 789.04 & 34.90 & 35.05 \\
\hline 23 & 36 & 4.65 & 0.55 & 2.60 & 20.00 & 0.25 & 770.40 & 765.61 & 36.66 & 36.90 \\
\hline 24 & 36 & 5.08 & 0.70 & 2.95 & 5.00 & 0.30 & 605.92 & 611.19 & 35.97 & 36.01 \\
\hline 25 & 36 & 5.50 & 0.85 & 3.30 & 8.75 & 0.10 & 527.13 & 526.30 & 33.54 & 33.46 \\
\hline 26 & 25.4 & 4.7 & 0.748 & 3.1 & 9.53 & 0.255 & 488.62 & 483.69 & 36.59 & 36.41 \\
\hline 27 & 0.5 & 5.093 & 0.885 & 3.59 & 5.68 & 0.183 & 375.29 & 380.79 & 31.47 & 31.64 \\
\hline 28 & 31.05 & 5.144 & 0.624 & 3.947 & 18.07 & 0.11 & 504.19 & 510.02 & 34.01 & 33.62 \\
\hline 29 & 16.87 & 4.3 & 0.774 & 3.507 & 8.95 & 0.156 & 444.71 & 436.37 & 36.46 & 36.73 \\
\hline 30 & 25.02 & 5.46 & 0.546 & 3.347 & 6.58 & 0.3 & 429.47 & 427.33 & 34.48 & 34.43 \\
\hline 31 & 10.24 & 3.87 & 0.577 & 3.135 & 9.515 & 0.28 & 447.07 & 465.53 & 38.51 & 38.73 \\
\hline 32 & 6.696 & 4.79 & 0.448 & 3.241 & 18.58 & 0.152 & 412.10 & 401.96 & 37.189 & 37.16 \\
\hline 33 & 23.25 & 4.39 & 0.463 & 2.86 & 6.16 & 0.187 & 495.95 & 506.34 & 38.365 & 38.56 \\
\hline 34 & 21.55 & 5.334 & 0.745 & 2.943 & 17.91 & 0.115 & 420.82 & 424.14 & 34.036 & 34.89 \\
\hline 35 & 31.64 & 5.49 & 0.543 & 3.528 & 14.39 & 0.294 & 476.86 & 472.29 & 34.167 & 33.80 \\
\hline
\end{tabular}

No. 1-25, learning set; No. 26-35, testing set. MTS represents maximum tensile stress. TRF represents total reaction force.

outside the orthogonal array was used to supervise the learning process. The input quantities were normalized to a range from -1 to 1 , and the output quantities were normalized to a range from 0 to 1 . The initial weights and the biases between -1 to 1 were randomly assigned. Both learning rate and the coefficient of momentum term were set at 0.5 . The new weight and bias were updated as the error between the predicted and the target performance was minimized. Generally, the learning and testing errors kept decreasing during computing iterations. The process was terminated when the testing errors were minimal. The ANN models were run 100 times with different initial weights, and the best model with the least test error was selected for optimization study. The ANN is coded by Microsoft Visual Basic (Redmond, WA).
2.4. Multiobjective Optimization with GAs. GA is commonly used for multiobjective optimization by using stochastic operators (Figure 4). The biobjective problem of the screw functions could be expressed by an aggregated weighted-sum fitness function $(F): F=w \cdot F_{\text {bending }}+(1-w) \cdot F_{\text {pullout }}$, where $F_{\text {bending }}$ was the normalized objective function of bending; $F_{\text {pullout }}$ was the normalized objective function of pullout; $w$, the given weight, was systematically changed from 0 to 1 to assess the different combinations of both performances. Both objective functions were transformed into the-larger-thebetter problem before aggregation, and the fitness function $(F)$ was maximized. The algorithm was initiated with a population with 40 randomly selected chromosomes. Each chromosome was composed of six design parameters with 


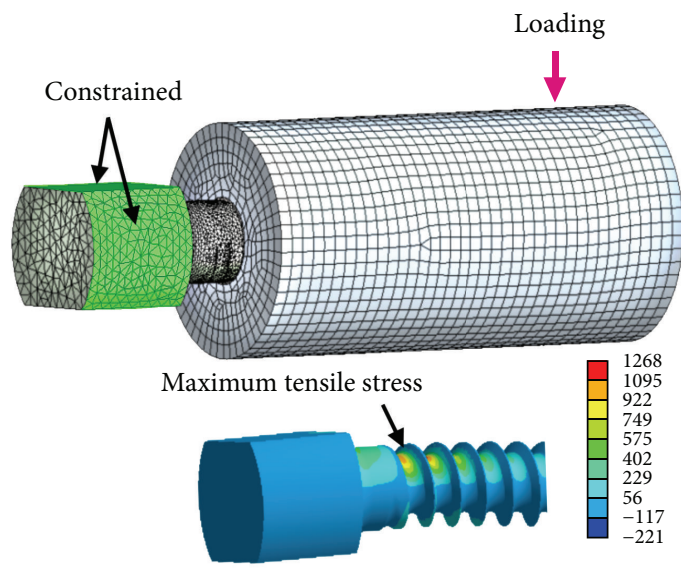

(a)

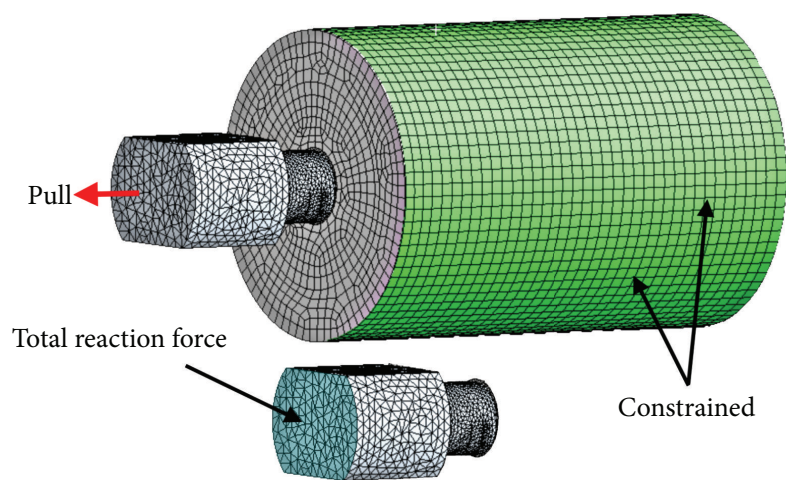

(b)

FIgURE 2: Finite element models: bending (a) and pullout (b).

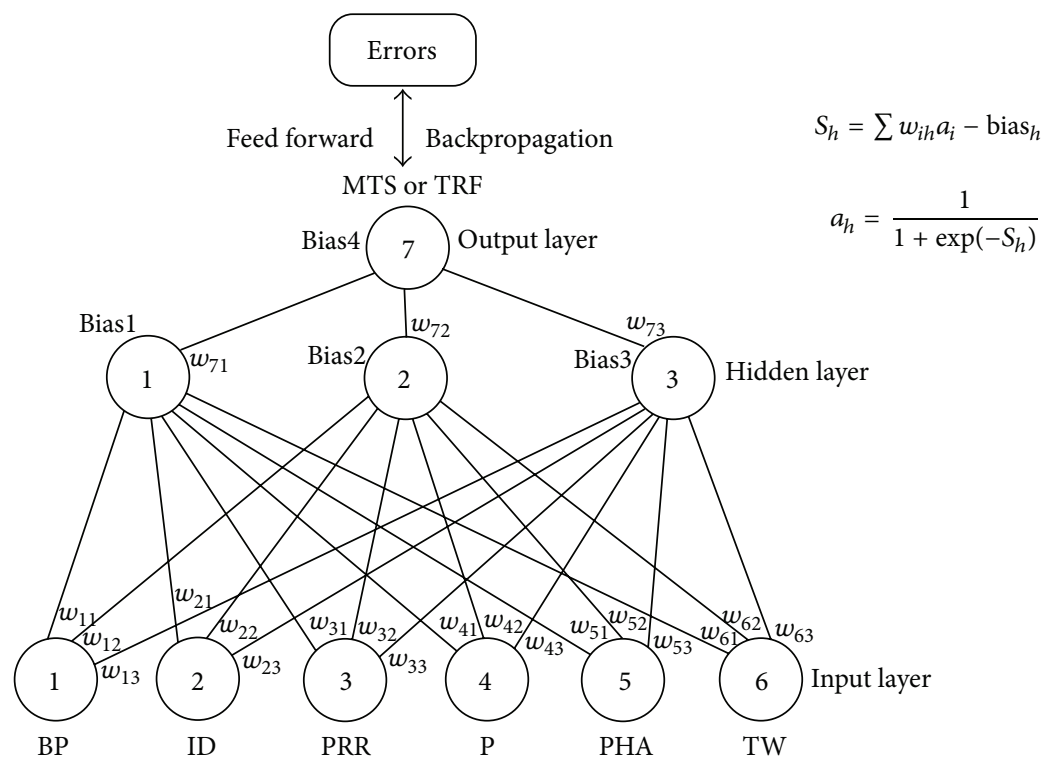

FIGURE 3: Three-layer feed-forward error-backpropagation neural network model.

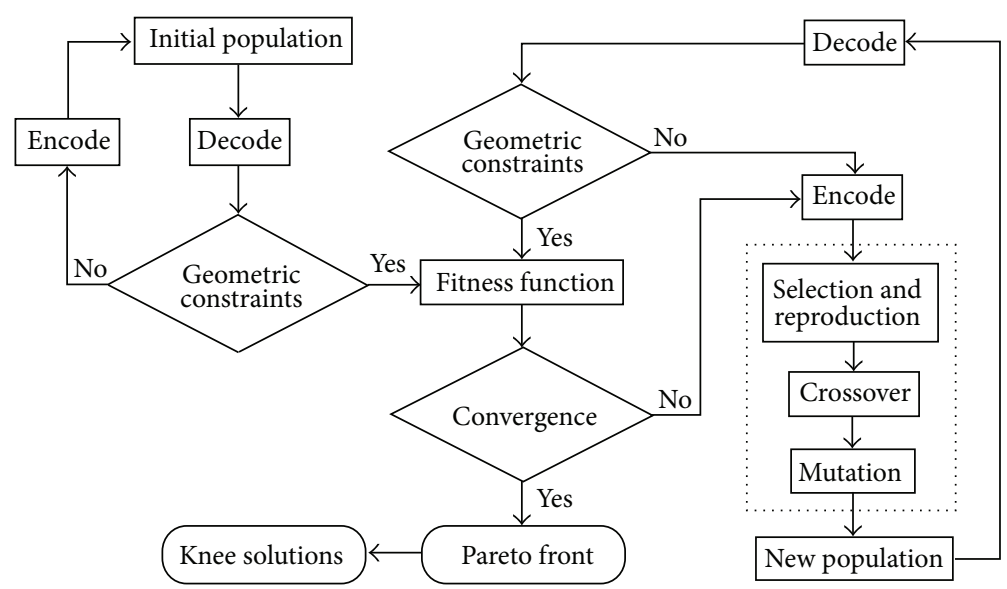

FIGURE 4: Flowchart of evolutionary optimality in GAs. 


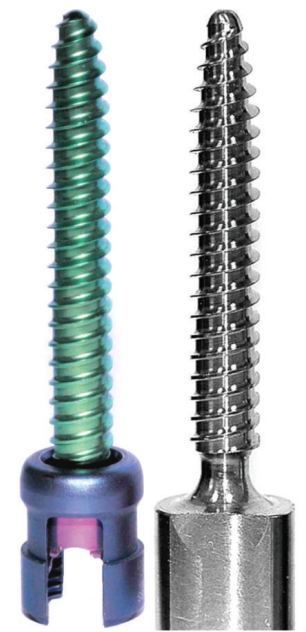

(a)

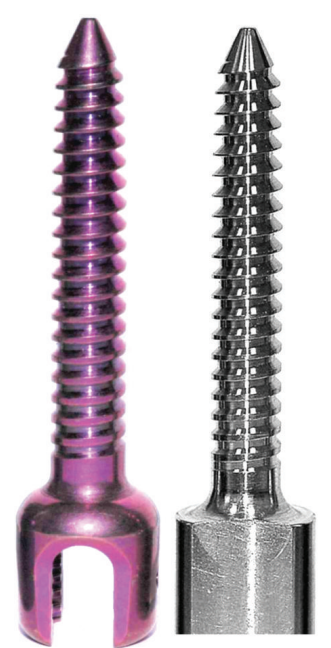

(b)

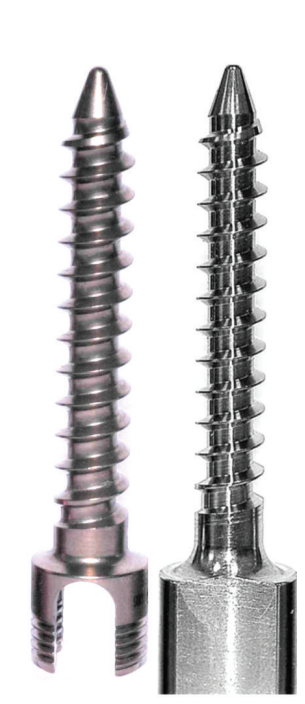

(c)

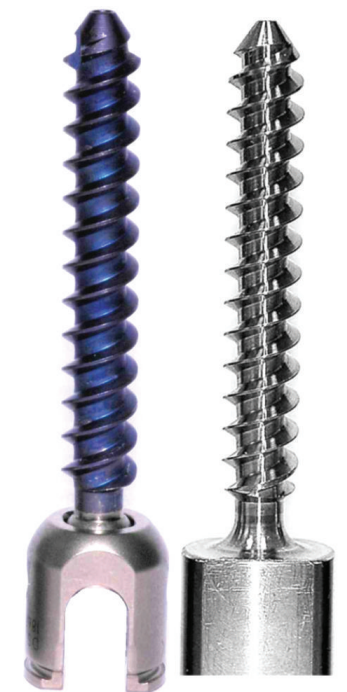

(d)

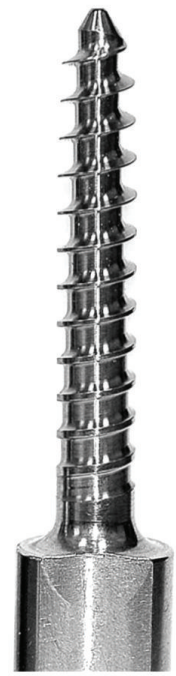

(e)

FIgure 5: Tested pedicle screws: (a) Synthes, (b) A-Spine, (c) Moss Miami, (d) Viper, and (e) Optimal.

42 bits of zeros and ones. The optimization process included selection, reproduction, and termination. Roulette wheel selection replicates the fitter solutions found in the population. Then a second generation population was reproduced from those selected through genetic operators: crossover and mutation. The crossover rate and the mutation rate were $90 \%$ and $1 \%$, respectively. If the new generations fulfilled the constraints, the fitness of the new populations was calculated and reselected again. The process was repeated and terminated until the highest ranking solution's fitness converged. The program of GAs was also developed by Microsoft Visual Basic. The optimization strategy produced a set of Pareto front with nondominant solutions, which meant there were no solutions better than those in both objectives. The optimal design range at the knee region of the Pareto front was subjectively defined as a less than $2 \%$ difference between the normalized objectives. The knee solutions were validated with FE analyses and compared with the commercially available pedicle screws. Ten thousand randomly selected screw designs were used to validate the Pareto set obtained in GA.

2.5. Mechanical Validation Tests. The results in the mathematical studies were validated by mechanical tests as conducted in the literature [1]. One optimal design randomly selected from the knee region of the Pareto front was compared with the four commercially available pedicle screws with a $7 \mathrm{~mm}$ outer diameter in both bending and pullout tests: Synthes (Synthes, Paoli, PA, USA), A-Spine (A-Spine Asia, Taipei, Taiwan), Moss Miami, and Viper (DePuy Spine, Raynham, MA, USA) (Figure 5). The structures of the commercial screws were measured by measuring microscope (Meiji MC50T, New York Microscope, Hicksville, NY). To make the comparison fair, the screws were manufactured with the same titanium alloy by the same process. The mechanical tests were conducted on a materials testing machine (Bionix 858, 


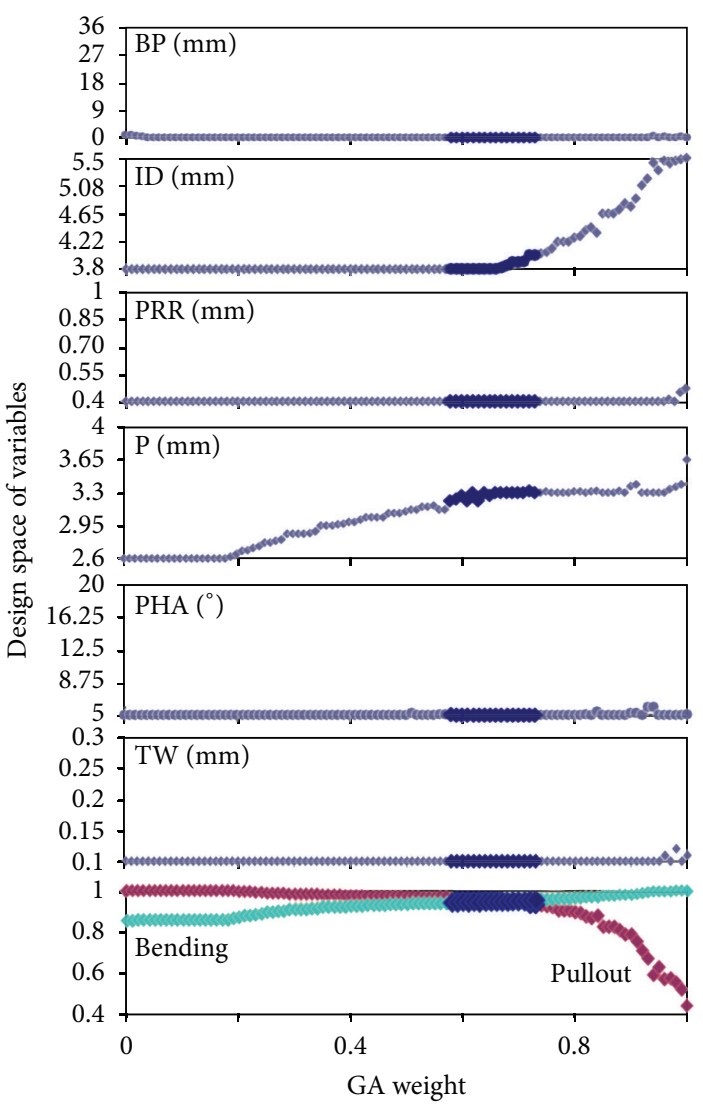

(a)

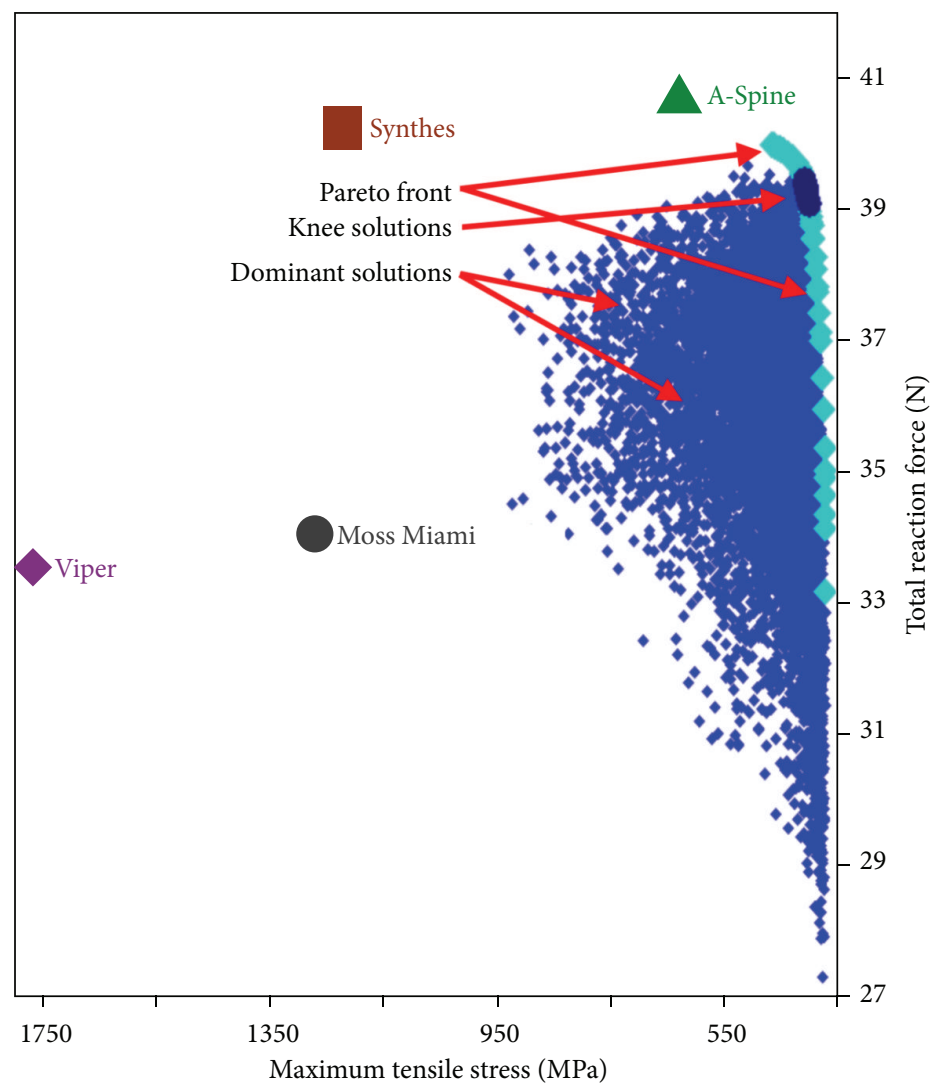

(b)

FIGURE 6: Optimization results: (a) changes of the values of structural variables related to the normalized objective functions of bending and pullout corresponding to given weights in GA. (b) Pareto plot with knee solutions.

MTS Corporation, Minneapolis, MN, USA), and the testing setup was similar to that in the FE models. In bending, polyoxymethylene cylinders (Universal Plastics, Auckland, New Zealand) representing the vertebrae could eliminate the interspecimen variability and prevent specimen failure during experiments. Sinusoidal waveform cyclic loading fatigue tests with a frequency of $10 \mathrm{~Hz}$ were performed with screws submerged in a saline bath at $37^{\circ} \mathrm{C}$. The maximal load of the cyclic testing was $410 \mathrm{~N}$ with a stress ratio of $10 \%$. The tests were terminated when the screws cracked or the number of testing cycles was more than one million [6]. The number of cycles at failure was recorded. For pullout, cellular polyurethane foam (Pacific Research Laboratories, Vashon, WA, USA) conforming to the standard of ASTM F1839-97 [20] can prevent the widely varying testing results. Two densities of the foam -0.32 and $0.16 \mathrm{gm} / \mathrm{cm}^{3}$ with a compressive modulus of 137.5 and $23 \mathrm{MPa}$ and a porosity of $71 \%$ and $86 \%$, respectively - were used to simulate cancellous bones with osteoporosis. For a fair comparison, the predrill hole was the same size as that of the ID of each screw at the screw tip. Thus, the conical screws could generate bone compaction during screw insertion. The screws were freely extracted in longitudinal direction with a loading rate of $5 \mathrm{~mm} / \mathrm{minute}$. The maximum load was defined as the pullout strength.

\section{Results}

In FE analyses, total element number ranged from 122,550 to 189,224 for bending and from 142,066 to 278,211 for pullout. The maximum tensile stress in bending tests was located at the proximal threads near the screw hub. The pedicle screws in pullout tests had negligible deformation because the bone was assumed osteoporotic (Figure 2). These two findings were compatible with the results in the mechanical tests. In ANN analyses, the computing iteration was 10000 cycles for bending and 5000 cycles for pullout. The differences between prophetic outputs obtained in ANN models and FE results were minimal. For bending, the mean absolute error was $1 \%$ $(0.05 \sim 3 \%)$ for learning and $1.64 \%(0.03 \sim 4.13 \%)$ for testing. For pullout, the mean absolute error was $0.4 \%(0.03 \sim 0.88 \%)$ for learning and $0.78 \%(0.08 \sim 2.51 \%)$ for testing.

The solutions of GA converged after 300 generations (see Supplementary Materials available at http://dx.doi.org/ $10.1155 / 2013 / 462875)$. The main factors that affected the Pareto set were ID and pitch (Figure 6), which increased along with the weight $(w)$. In the knee region, the weight ranged from 0.60 to 0.72 . The corresponding range of the structural variables was 3.8 to $4.06 \mathrm{~mm}$ for ID and 3.21 to $3.3 \mathrm{~mm}$ for pitch; the fixed variables were $0 \mathrm{~mm}$ for BP, $0.4 \mathrm{~mm}$ for PRR, $5^{\circ}$ for PHA, and $0.1 \mathrm{~mm}$ for TW. The bending 
TABLE 2: Structures and results of FE analyses and mechanical tests of four commercially available pedicle screws and the optimal design. Values were expressed as mean (standard deviation).

\begin{tabular}{|c|c|c|c|c|c|}
\hline Mechanical properties & Synthes type & A-Spine type & Moss Miami type & Viper type & Optimal design \\
\hline $\mathrm{BP}(\mathrm{mm})$ & 0 & 0 & 40 & cylindrical & 0 \\
\hline $\mathrm{CD}(\mathrm{mm})$ & 2.76 & 4 & 4.61 & 4.4 & 3.8 \\
\hline $\operatorname{PRR}(\mathrm{mm})$ & 0.22 & 0.1 & 3 & 3 & 0.4 \\
\hline $\mathrm{P}(\mathrm{mm})$ & 2 & 2 & 2.95 & 2.87 & 3.3 \\
\hline $\operatorname{PHA}\left({ }^{\circ}\right)$ & 0 & 0 & 31.35 & 29.93 & 5 \\
\hline TW (mm) & 0.1 & 0.1 & 0.2 & 0.33 & 0.1 \\
\hline Maximum tensile stress $(\mathrm{MPa})$ & 1220 & 628 & 1268 & 1766 & 422 \\
\hline Total reaction force $(\mathrm{N})$ & 40.25 & 40.77 & 33.53 & 34.04 & 39.1 \\
\hline Fatigue life $\left(10^{3}\right.$ cycles $)$ & $13.77(4.62)$ & $46.53(15.9)$ & $8.52(1.35)$ & - & $>1000$ \\
\hline Pullout strength, $0.32 \mathrm{~g} / \mathrm{cm}^{3}(\mathrm{~N})$ & $2148(144)$ & $2068(117)$ & $1598(56)$ & $1553(84)$ & $2009(74)$ \\
\hline Pullout strength, $0.16 \mathrm{~g} / \mathrm{cm}^{3}(\mathrm{~N})$ & $1015(74)$ & $951(48)$ & $705(48)$ & $662(63)$ & $825(52)$ \\
\hline
\end{tabular}

Cyclic loading tests of Viper type screws were not completed because the screws yielded quickly during the tests.

strength and the pullout strength ranged between $92 \%$ and $94 \%$ of their maxima. The exactitude of knee solutions closely approximated the results of FE analyses. The ten thousand randomly selected screw designs were all dominant solutions in Pareto plot. The commercially available pedicle screws were far away from the knee solutions. The A-Spine and Synthes type screws had high pullout strength but relatively low bending strength. Moss Miami and Viper type screws were low in both bending strength and pullout strength.

In the mechanical tests, the logarithm of the fatigue life was closely related to the maximum tensile stress obtained in FE analyses with a correlation coefficient of $-0.91(P<$ 0.01 ), and the pullout strength was closely related to the total reaction force with a correlation coefficient of $0.93(P<$ 0.01 ) (Table 2 ). The optimal designs had significantly higher fatigue lives ( $>10^{6}$ cycles) than all the commercial screws by an analysis of variance test $(P<0.01$, resp.), and pullout strength was higher than Moss Miami and Viper screws $(P<$ 0.01 for both foam densities). Synthes and A-Spine screws had higher pullout strength than optimal designs, but the bending strength was relatively low because of a very small pitch $(2 \mathrm{~mm})$. This was compatible with the findings in FE analyses.

\section{Discussion}

In order to reduce the incidence of fixation failure in shortsegment fixation for spinal fractures, different kinds of interventions have been developed, including combined anterior instrumentation [21], bone cement augmentation [22], transpedicular vertebroplasty [23], and so forth. However, these methods are threatened by complications [1]. Improvement of the pedicle screw design to achieve better bending strength and bone holding power is still the most basic step to prevent failure of fixation. Investigating only one mechanical performance of bending strength or pullout strength of the pedicle screws exclusively might lead to undetected compromise of the other one, because these two objectives would conflict with each other in the design process $[1,15]$. In the present study, with adequate control of the design space, the two mechanical performances of the screws were investigated simultaneously with ANN and GA for multiobjective optimization analysis.

FE analysis, a powerful tool for biomechanical researches on structures with complicated loading and boundary conditions $[24,25]$, can be reliably used for predicting the bending strength and pullout strength of orthopedic screws $[17,18]$. In the present study, the FE models could be well validated by mechanical tests in both bending and pullout tests with very high correlation coefficients. However, because of the sophisticated computation process, FE analyses are not suitable for multiobjective design optimization studies. Therefore, the ANN algorithms, which have the special advantage of functional approximation with fast computation, can be used as surrogate functions of FE models for multiobjective optimization studies.

ANN, a nonlinear statistical data modeling tool, uses learning rules to develop models and parallel computing to find answers. These neurocomputing procedures mimic information processing and knowledge acquisition in human brains. ANN can construct complex relationships between input variables and output performances and process not only values but also texts, images, and voices $[19,26]$. Its attractiveness comes from the remarkable information processing characteristics of the biological systems such as nonlinearity with better fit to the data, high parallelism, robustness, fault tolerance, learning, ability to handle imprecise and fuzzy information, and their capability to generalize. Our previous optimization study of tibial locking screws developed objective functions with least-squares linear regression models [15]. However, with more complex trends in the conical core design of pedicle screws in the present study, linear regression analysis with high order polynomials might fit badly at the extreme of the independent variables or in data with limiting behaviors, because polynomials do not have asymptotics [27]. ANN viewed as generalizations of "super regression" can outperform statistical regression with regard to prediction accuracy. This superiority increases as the dimensionality and/or nonlinearity of the problem increases. Classically, development of an $\mathrm{ANN}$ requires partitioning of the parent 
database. This may decrease the statistical power. In the present study, use of all the datasets in the orthogonal array in the training and 10 testing datasets randomly selected from the entire parametric space outside the orthogonal array could avoid this disadvantage and increase the predictability.

Many real-world problems involve multiple competing objectives. The two objectives of pedicle screws, bending strength and pullout strength, are conflicting and characterized by the fact that improving one objective may jeopardize the other [15]. The present multiobjective optimization study used a weighted-sum function and GA to develop Pareto optima that were trade-off solutions for the conflicting objectives [28]. The solutions at the knee region of the Pareto front, characterized by the fact that a small improvement in either objective might cause a substantial change in the other, were considered the most suitable trade-offs (the optimal designs) by designers. The bending strength and the pullout strength of the optimal designs ranged between $92 \%$ and $94 \%$ of their maxima. This indicated that with minimal compromise of one objective, the other still could maintain a relatively high performance. However, this multiobjective optimization principle is not adequately considered in the design of commercially available pedicle screws. The Synthes and A-Spine type screws with a very small pitch $(2 \mathrm{~mm})$ had very high pullout strength, but such a small pitch led to a sharp root radius and high tensile stress. A small increase of maximum tensile stress might markedly decrease the fatigue life because of the logarithmic relationship. This was the reason why small pitch was not included in the design space of the present study. In contrast, both Viper and Moss Miami type screws with a cylindrical core had low bending and pullout strength. They were dominated designs, very far away from the knee region. Basically, tapering of the ID from the screw tip all the way to the screw hub may increase the bending strength and pullout strength simultaneously. Especially, elimination of the step-off at the screw hub can increase the fatigue strength substantially [1]. This explained higher fatigue life in A-Spine type and optimal design screws. Viper type screws with a smaller core at the screw hub for better adjustability of the polyaxial design might jeopardize the bending strength extremely.

The present study has potential pitfalls. First, ANN is an empirical model and its success depends on both the quality and quantity of the data. Although only 25 datasets were used for training, the ANN model still could accurately reflect the FE results, because the orthogonal array could fairly represent the entire parametric space and the FE data were relatively noise free, as compared with clinical data. Second, a different outer diameter and range of design space might affect the ranges of the optimal design. The present study considered only screws with an outer diameter of $7.0 \mathrm{~mm}$, but the design space could cover the important ranges of the pedicle screw design. Third, GAs are stochastic iterative processes and do not guarantee a global optimality. However, the optimal designs in the present study with fitness levels up to $92 \%$ or $94 \%$ of their maxima were already practically acceptable. Fourth, the ANN is criticized as a "black box" method. One cannot exactly explain what interactions are modeled in the hidden layers, and there is still no specific method to define the optimal hidden layers. However, these did not affect the method's robustness in the present optimization study. Last, the optimal design was closely related to the relative weight between the bending strength and pullout strength (1:1 in the present study). The selection depended on the factors linked to the problem and a thorough knowledge of them.

In conclusion, the ANN model could reliably approximate the results of sophisticated mathematical analyses of pedicle screws. The model could be used to solve the problems of conflicting objectives of pedicle screws with evolutionary GA. The trade-off optimal solutions obtained in this optimization study could achieve an ideal with high performance in both bending and pullout tests. The present method proves beneficial to both manufacturers who design implants and surgeons who select the best product to prevent failure in the treatment of spine fractures.

\section{Conflict of Interests}

There is no conflict of interests in the present study.

\section{Acknowledgment}

The present study was financially supported by National Science Counsel, Grant no. NSC 98-2320-B-002-007-MY3.

\section{References}

[1] C.-K. Chao, C.-C. Hsu, J.-L. Wang, and J. Lin, "Increasing bending strength and pullout strength in conical pedicle screws: biomechanical tests and finite element analyses," Journal of Spinal Disorders \& Techniques, vol. 21, no. 2, pp. 130-138, 2008.

[2] P. L. Sanderson, R. D. Fraser, D. J. Hall, C. M. J. Cain, O. L. Osti, and G. R. Potter, "Short segment fixation of thoracolumbar burst fractures without fusion," European Spine Journal, vol. 8, no. 6, pp. 495-500, 1999.

[3] P. G. Katonis, G. M. Kontakis, G. A. Loupasis, A. C. Aligizakis, J. I. Christoforakis, and E. G. Velivassakis, "Treatment of unstable thoracolumbar and lumbar spine injuries using CotrelDubousset instrumentation," Spine, vol. 24, no. 22, pp. 23522357, 1999.

[4] A. R. Vaccaro, D. H. Kim, D. S. Brodke et al., "Diagnosis and management of thoracolumbar spine fractures," Instructional Course Lectures, vol. 53, pp. 359-373, 2004.

[5] A. Mahar, C. Kim, M. Wedemeyer et al., "Short-segment fixation of lumbar burst fractures using pedicle fixation at the level of the fracture," Spine, vol. 32, no. 14, pp. 1503-1507, 2007.

[6] J. L. Stambough, F. El Khatib, A. M. Genaidy, and R. L. Huston, "Strength and fatigue resistance of thoracolumbar spine implants: an experimental study of selected clinical devices," Journal of Spinal Disorders, vol. 12, no. 5, pp. 410-414, 1999.

[7] D.-Y. Cho, W.-Y. Lee, P.-C. Sheu et al., "Treatment of thoracolumbar burst fractures with polymethyl methacrylate vertebroplasty and short-segment pedicle screw fixation," Neurosurgery, vol. 53, no. 6, pp. 1354-1361, 2003.

[8] K. E. Ponnusamy, S. Iyer, G. Gupta, and A. J. Khanna, "Instrumentation of the osteoporotic spine: biomechanical and clinical considerations," The Spine Journal, vol. 11, no. 1, pp. 54-63, 2011.

[9] J. S. Vanichkachorn, A. R. Vaccaro, M. J. Cohen, and J. M. Cotler, "Potential large vessel injury during thoracolumbar pedicle 
screw removal: a case report," Spine, vol. 22, no. 1, pp. 110-113, 1997.

[10] K. Willett, T. C. Hearn, and A. V. Cuncins, "Biomechanical testing of a new design for Schanz pedicle screws," Journal of Orthopaedic Trauma, vol. 7, no. 4, pp. 375-380, 1993.

[11] C.-C. Hsu, C.-K. Chao, J.-L. Wang, S.-M. Hou, Y.-T. Tsai, and J. Lin, "Increase of pullout strength of spinal pedicle screws with conical core: biomechanical tests and finite element analyses," Journal of Orthopaedic Research, vol. 23, no. 4, pp. 788-794, 2005.

[12] S. D. Cook, S. L. Salkeld, T. Stanley, A. Faciane, and S. D. Miller, "Biomechanical study of pedicle screw fixation in severely osteoporotic bone," The Spine Journal, vol. 4, no. 4, pp. 402-408, 2004.

[13] J. Lin, S.-J. Lin, H. Chiang, and S.-M. Hou, "Bending strength and holding power of tibial locking screws," Clinical Orthopaedics \& Related Research, no. 385, pp. 199-206, 2001.

[14] K. Okuyama, K. Sato, E. Abe, H. Inaba, Y. Shimada, and H. Murai, "Stability of transpedicle screwing for the osteoporotic spine: an in vitro study of the mechanical stability," Spine, vol. 18, no. 15, pp. 2240-2245, 1993.

[15] C.-C. Hsu, C.-K. Chao, J.-L. Wang, and J. Lin, "Multiobjective optimization of tibial locking screw design using a genetic algorithm: evaluation of mechanical performance," Journal of Orthopaedic Research, vol. 24, no. 5, pp. 908-916, 2006.

[16] C.-K. Chao, J. Lin, S. T. Putra, and C.-C. Hsu, "A neurogenetic approach to a multiobjective design optimization of spinal pedicle screws," Journal of Biomechanical Engineering, vol. 132, no. 9, Article ID 091006, 6 pages, 2010.

[17] S.-M. Hou, C.-C. Hsu, J.-L. Wang, C.-K. Chao, and J. Lin, "Mechanical tests and finite element models for bone holding power of tibial locking screws," Clinical Biomechanics, vol. 19, no. 7, pp. 738-745, 2004.

[18] C.-K. Chao, C.-C. Hsu, J.-L. Wang, and J. Lin, "Increasing bending strength of tibial locking screws: mechanical tests and finite element analyses," Clinical Biomechanics, vol. 22, no. 1, pp. 59-66, 2007.

[19] N. B. Karayiannis and A. N. Venetsanopoulos, Artificial Neural Networks: Learning Algorithms, Performance Evaluation, and Applications, Kluwer Academic, Boston, Mass, USA, 1993.

[20] R. F. Allen, N. C. Baldini, P. E. Donofrio, E. L. Gutman, E. Keefe, and J. G. Kramer, Standard Specification for Rigid Polyurethane Foam for Use as a Standard Material for Testing Orthopedic Devices and Instruments (F1839-97), The American Society for Testing and Materials, West Conshohocken, Penn, USA, 1998.

[21] P. M. Kallemeier, B. P. Beaubien, G. R. Buttermann, D. J. Polga, and K. B. Wood, "In vitro analysis of anterior and posterior fixation in an experimental unstable burst fracture model," Journal of Spinal Disorders \& Techniques, vol. 21, no. 3, pp. 216224, 2008.

[22] M.-C. Chang, C.-L. Liu, and T.-H. Chen, "Polymethylmethacrylate augmentation of pedicle screw for osteoporotic spinal surgery: a novel technique," Spine, vol. 33, no. 10, pp. E317-E324, 2008.

[23] A. Alanay, E. Acaroglu, M. Yazici, A. Oznur, and A. Surat, "Short-segment pedicle instrumentation of thoracolumbar burst fractures: does transpedicular intracorporeal grafting prevent early failure?" Spine, vol. 26, no. 2, pp. 213-217, 2001.

[24] F. H. Dar, J. R. Meakin, and R. M. Aspden, "Statistical methods in finite element analysis," Journal of Biomechanics, vol. 35, no. 9, pp. 1155-1161, 2002.
[25] M. Viceconti, S. Olsen, L.-P. Nolte, and K. Burton, "Extracting clinically relevant data from finite element simulations," Clinical Biomechanics, vol. 20, no. 5, pp. 451-454, 2005.

[26] S. Agatonovic-Kustrin and R. Beresford, "Basic concepts of artificial neural network (ANN) modeling and its application in pharmaceutical research," Journal of Pharmaceutical and Biomedical Analysis, vol. 22, no. 5, pp. 717-727, 2000.

[27] P. Royston and D. G. Altman, "Regression using fractional polynomials of continuous covariates: parsimonious parametric modelling," Applied Statistics, vol. 43, no. 3, pp. 429-467, 1994.

[28] I. Taga, A. Funakubo, and Y. Fukui, "Design and development of an artificial implantable lung using multiobjective genetic algorithm: evaluation of gas exchange performance," ASAIO Journal, vol. 51, no. 1, pp. 92-102, 2005. 


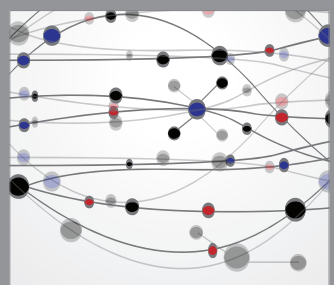

The Scientific World Journal
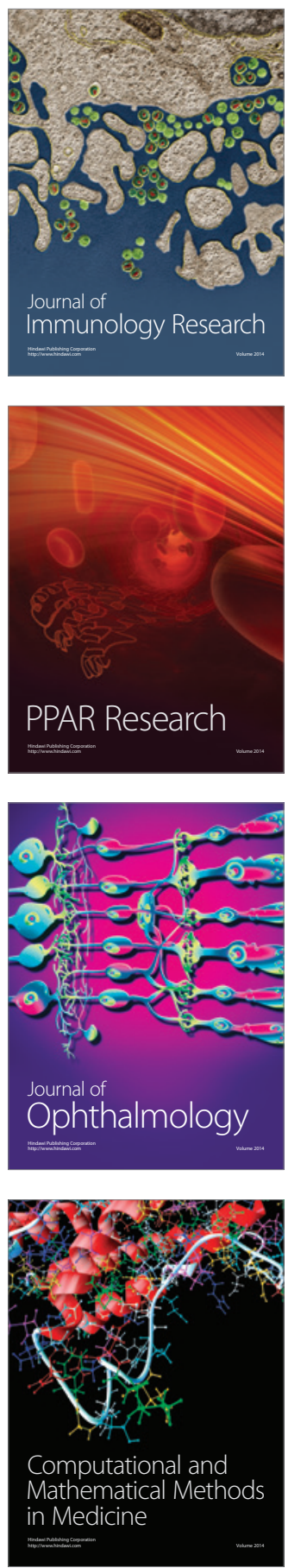

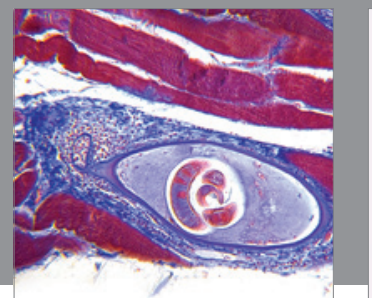

Gastroenterology

Research and Practice
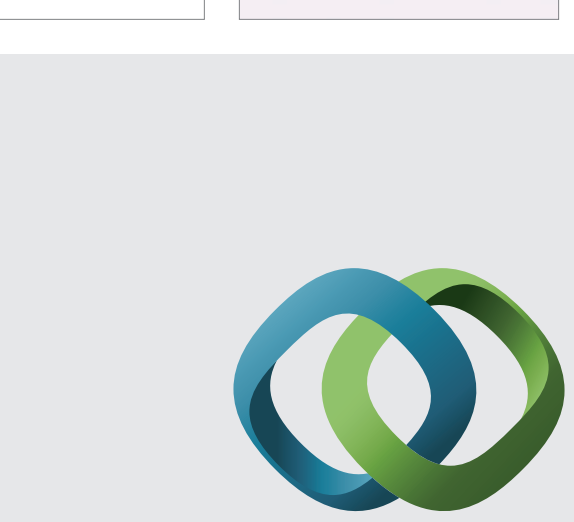

\section{Hindawi}

Submit your manuscripts at

http://www.hindawi.com
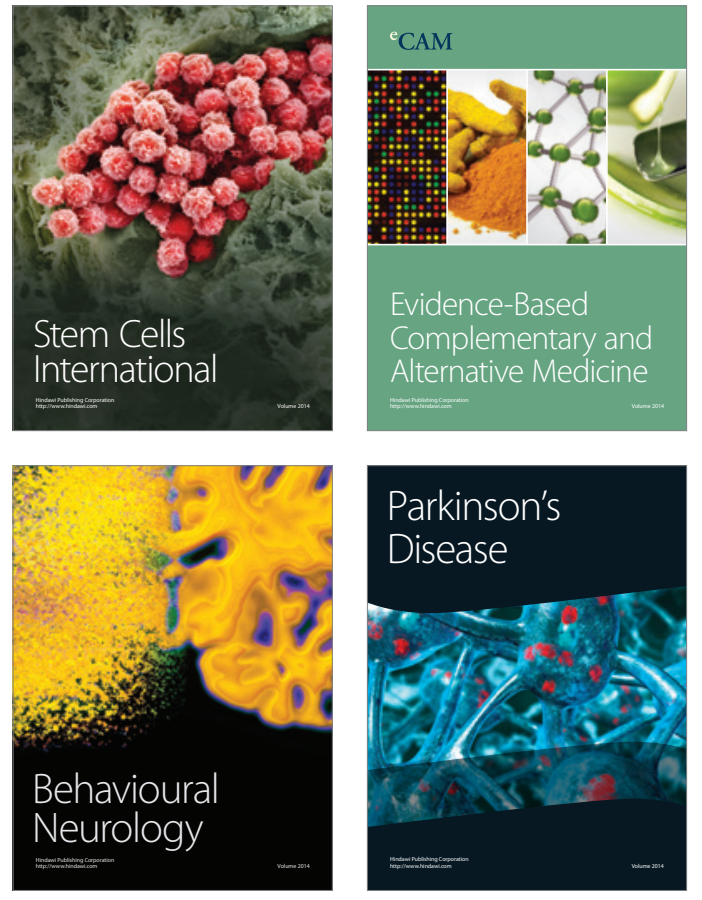
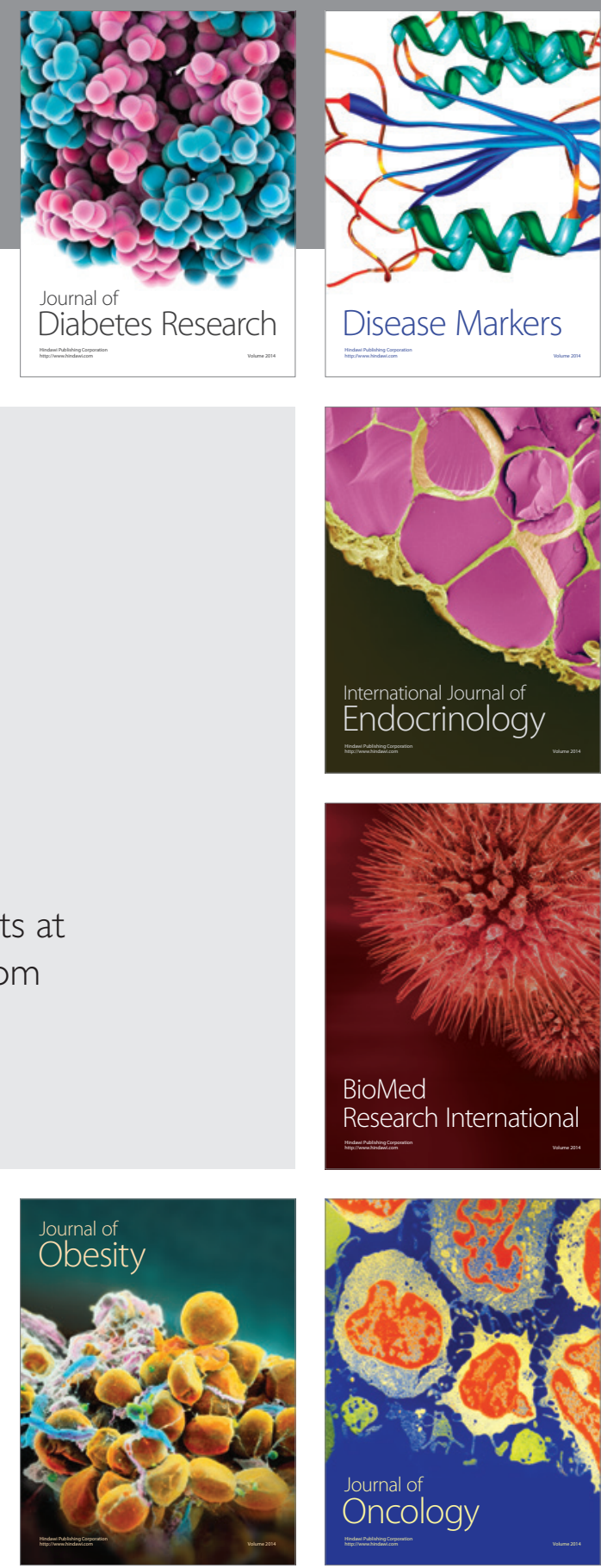

Disease Markers
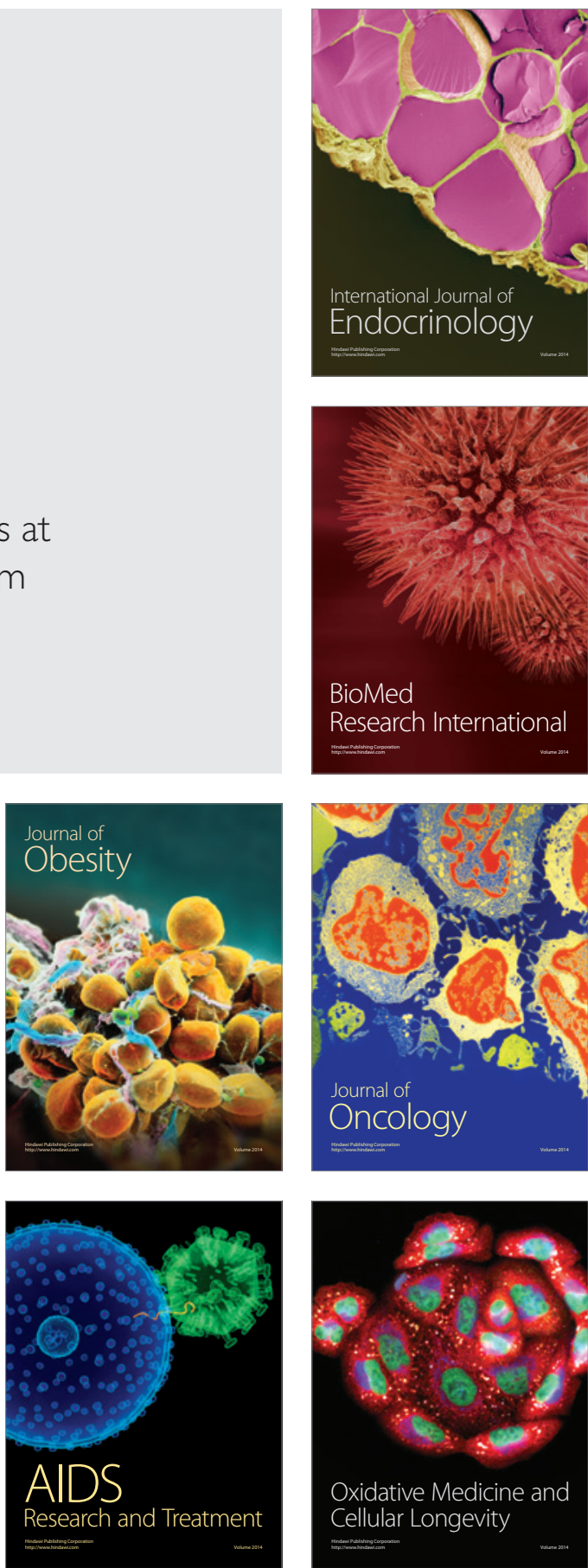